\title{
Connective tissue disease associated with pulmonary arterial hypertension: management of a patient with severe haemodynamic impairment
}

\author{
Olivier Sitbon ${ }^{1,2,3}$ and Laurent Bertoletti4,5
}

\begin{abstract}
Affiliations: ${ }^{1}$ Faculté de Médecine, Université Paris-Sud, Le Kremlin-Bicêtre, France. ${ }^{2} \mathrm{AP}-\mathrm{HP}$, Centre de Référence de l'hypertension pulmonaire sévère, Service de pneumologie et soins intensifs, Hôpital de Bicêtre, Le Kremlin-Bicêtre, France. ${ }^{3}$ INSERM U-999, LabEx LERMIT, Centre chirurgical Marie Lannelongue, Le Plessis-Robinson, France. "Service de Médecine Vasculaire et Thérapeutique, Hôpital Nord, CHU de SaintEtienne, Saint-Etienne, France. ${ }^{5}$ Université Jean-Monnet, Groupe de Recherche sur la Thrombose (EA 3065), Inserm, CIC1408, Saint-Etienne, France.
\end{abstract}

Correspondence: Olivier Sitbon, Service de pneumologie et soins intensifs, CHU de Bicêtre, 78 rue du Général Leclerc, F-94275 Le Kremlin-Bicêtre, France. E-mail: olivier.sitbonabct.aphp.fr

○

@ERSpublications

PAH associated with mixed connective tissue disease: management of a severe case http://ow.ly/CQHeY

Despite the availability of specific therapies targeting multiple pathways involved in the development and progression of pulmonary arterial hypertension $(\mathrm{PAH})$, and the improved survival observed in PAH patients in recent years, it remains a progressive, devastating disease [1]. Some encouraging evidence regarding the use of upfront triple-combination therapy in the management of patients with advanced disease has been previously reported [2]. This article reports the management of a patient diagnosed with severe PAH (New York Heart Association (NYHA) functional class IV) who was referred to the national pulmonary hypertension reference centre. The article highlights important considerations for timely and accurate diagnosis of PAH and exhaustive aetiological evaluation. It provides key insights into the management of patients presenting with severe disease, with particular focus on their treatment with multiple PAH-specific therapies.

This is the case of a 20-year-old female patient who was seen by her general practitioner with symptoms of inflammatory arthralgia (fingers, wrists and knees), which she had been experiencing for several months (since December 2010), associated with a long history of Raynaud's phenomenon. The patient was a nonsmoker, was not on any therapy (except the oral contraceptive pill), and did not have a history of taking appetite suppressants. She had no family history of PAH. A rheumatological assessment was initiated, and despite tests for rheumatoid factor and anti-cyclic citrullinated peptide being negative, rheumatoid arthritis was initially suspected. Treatment with nonsteroidal anti-inflammatory drugs followed by methotrexate proved to be ineffective and was stopped in September 2012 after 21 months.

In February 2013, the patient presented with a 1-month history of worsening dyspnoea following exertion, dizziness and palpitations. Her general practitioner referred her to a cardiologist for an ECG which revealed sinus tachycardia, thus, she was prescribed a $\beta$-blocker. The patient's clinical status rapidly deteriorated and

Received: Sept 292014 | Accepted after revision: Oct 142014

Conflict of interest: Disclosures can be found alongside the online version of this article at err.ersjournals.com

Provenance: Publication of this peer-reviewed article was sponsored by Actelion Pharmaceuticals Ltd, Allschwil, Switzerland (principal sponsor, European Respiratory Review issue 134).

Copyright OERS 2014. ERR articles are open access and distributed under the terms of the Creative Commons Attribution Non-Commercial Licence 4.0. 
she was referred to a university hospital (Centre Hospitalier Universitaire, Saint-Etienne, France) where she presented with dyspnoea when resting along with chest pains. A physical examination performed at the emergency department reported the following: body mass index $19.7 \mathrm{~kg} \cdot \mathrm{m}^{-2}$; blood pressure $100 / 60 \mathrm{mmHg}$; heart rate 82 beats $\cdot \mathrm{min}^{-1}$; arterial oxygen saturation measured by pulse oximeter $96 \%$; jugular distension; hepatalgia; hepatomegaly; and loud P2 heart sounds. Her blood haemoglobin level was $13.2 \mathrm{~g} \cdot \mathrm{dL}^{-1}$, sodium was $139 \mathrm{mmol} \cdot \mathrm{L}^{-1}$, creatinine was $72 \mu \mathrm{mol} \cdot \mathrm{L}^{-1}$, and her aspartate aminotransferase and alanine aminotransferase levels were approximately twice the upper limit of normal. Prothrombin time was $60 \%$, D-dimer levels were elevated $\left(>6000 \mu \mathrm{g} \cdot \mathrm{L}^{-1}\right)$, brain natriuretic peptide (BNP) levels were $1128 \mathrm{ng} \cdot \mathrm{L}^{-1}$ and $\beta$-human chorionic gonadotropin was negative.

A chest radiograph performed at the emergency department showed dilatation of the main pulmonary artery and also a degree of cardiomegaly. High-resolution computed tomography of the chest showed enlargement of the main pulmonary artery, dilation of the right atrium and right ventricle (with compression of the left ventricle), and dilation of the hepatic veins. No signs of proximal or distal pulmonary embolism or parenchymal abnormalities were seen. Transthoracic echocardiography showed: normal left heart function (ejection fraction 50\%) with no atrial or ventricular defect; right atrial and right ventricle dilation; impaired right ventricle function (tricuspid annular plane systolic excursion $12 \mathrm{~mm}$, $S$ wave $8 \mathrm{~cm} \cdot \mathrm{s}^{-1}$ ); paradoxical septal motion; estimated right ventricle systolic pressure $\sim 89 \mathrm{mmHg}$ (tricuspid regurgitant jet velocity $\sim 4.30 \mathrm{~m} \cdot \mathrm{s}^{-1}$ and estimated right atrial pressure (RAP) $\sim 15 \mathrm{mmHg}$ ); and moderate pericardial effusion.

The patient was referred to the national pulmonary hypertension reference centre (Centre de Référence de l'hypertension pulmonaire sévère, Hôpital Bicêtre, Université Paris-Sud, Le Kremlin-Bicêtre, France) and was immediately admitted to the intensive care unit as she was in NYHA functional class IV, had severe right heart failure, normal blood pressure $(98 / 60 \mathrm{mmHg})$, and $98 \%$ arterial oxygen saturation measured by pulse oximeter on room air. The patient was treated with high-dose intravenous diuretics $(250 \mathrm{mg}$ furosemide drip for $24 \mathrm{~h}$ ), small-dose dobutamine $\left(5 \mu \mathrm{g} \cdot \mathrm{kg}^{-1} \cdot \mathrm{min}^{-1}\right)$ and anticoagulants (low-molecularweight heparin). Blood tests were negative for HIV and hepatitis B and C virus, no coagulation disorders were present (no antiphospholipid antibodies) and rheumatoid factor testing was negative. However, antinuclear antibodies were positive (1/1280), with elevated anti-ribonucleoprotein levels (357 IU).

The completed work-up included a lung ventilation/perfusion scan that showed normal lung perfusion and no evidence of pulmonary thromboembolism. Abdominal ultrasonography was also performed to check for liver diseases and portal hypertension, but these were negative. Pulmonary function tests showed normal volume and flow, and included forced vital capacity (FVC; 74\% predicted), forced expiratory volume in $1 \mathrm{~s} \mathrm{(FEV1;}$ $70 \%$ predicted), FEV1/FVC (82\%) and total lung capacity ( $81 \%$ predicted). Diffusing capacity of the lung for carbon monoxide (DLCO) was low (40\% predicted). When corrected for alveolar volume, DLCO/alveolar volume was $70 \%$ predicted. Arterial blood gases reported an arterial oxygen tension and arterial carbon dioxide tension of $89 \mathrm{mmHg}$ and $28 \mathrm{mmHg}$, respectively. After a few days of i.v. diuretics and inotropic drugs, the 6-min walking distance (6MWD) was $220 \mathrm{~m}$, including two stops; with a high Borg score of 6, no desaturation and no increase in heart rate; the patient's BNP level was still elevated $\left(802 \mathrm{ng} \cdot \mathrm{L}^{-1}\right)$.

Right heart catheterisation after withdrawal of dobutamine therapy indicated that haemodynamic parameters were severely impaired, with a RAP of $12 \mathrm{mmHg}$, mean pulmonary arterial pressure (mPAP) of $57 \mathrm{mmHg}$, pulmonary artery occlusion pressure of $4 \mathrm{mmHg}$, low cardiac output of $2.40 \mathrm{~L} \cdot \mathrm{min}^{-1}$, low cardiac index of $1.60 \mathrm{~L} \cdot \mathrm{min}^{-1} \cdot \mathrm{m}^{-2}$, high pulmonary vascular resistance (PVR) of 22 Wood units and a mixed venous oxygen saturation of $49 \%$. Acute vasodilator testing (inhaled nitric oxide) was negative with no change in mPAP $(58 \mathrm{mmHg}$ ). Following these assessments, the patient was diagnosed with severe PAH in association with mixed connective tissue disease (CTD), was in NYHA functional class IV with right heart failure at presentation and was non-vasoreactive. The diagnosis of mixed CTD was based on the patient's clinical presentation with arthralgia and Raynaud's phenomenon, and the presence of a very elevated anti-ribonucleoprotein level.

Based on the risk assessment from the 2009 European Society of Cardiology/European Respiratory Society guidelines [3], it was determined that this patient was unstable and deteriorating, and had a poor prognosis (table 1). Upfront triple-combination therapy with i.v. epoprostenol $\left(12 \mathrm{ng} \cdot \mathrm{kg}^{-1} \cdot \mathrm{min}^{-1}\right)$ was initiated in addition to bosentan (125 mg twice daily) and tadalafil (40 mg once daily). Additional immunosuppressive therapy was started in order to improve pulmonary vascular disease in the form of oral corticosteroids (prednisone $0.5 \mathrm{mg} \cdot \mathrm{kg}^{-1} \cdot \mathrm{day}^{-1}$ ) and i.v. cyclophosphamide pulses $\left(600 \mathrm{mg} \cdot \mathrm{m}^{-2}\right.$ every 4 weeks, reassessed after six pulses). After 6 months, the patient was assessed and, compared with baseline, improvements included a change in NYHA functional class from IV to I, an improvement in 6MWD from 220 to $487 \mathrm{~m}$, and normalisation of haemodynamic parameters: RAP (12 to $7 \mathrm{mmHg}$ ), mPAP (57 to $20 \mathrm{mmHg}$ ), cardiac output (2.4 to $6.6 \mathrm{~L} \cdot \mathrm{min}^{-1}$ ) and PVR (22 to 1.4 Wood units). 
TABLE 1 Patient risk assessment

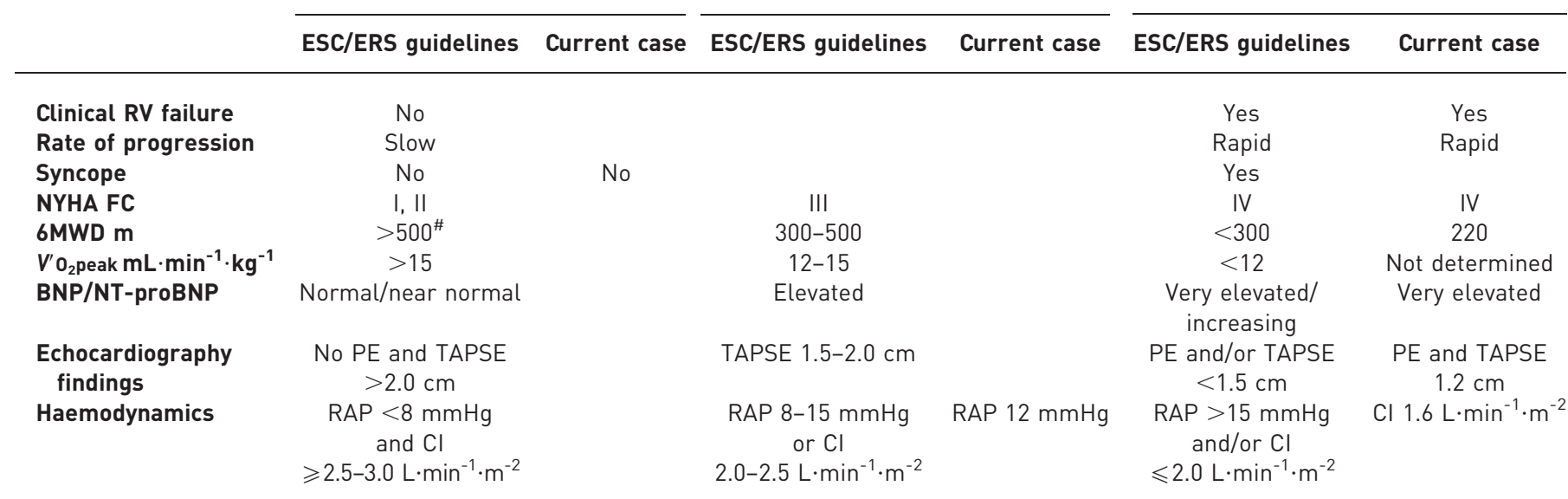

ESC: European Society of Cardiology; ERS: European Respiratory Society; RV: right ventricular; NYHA: New York Heart Association; FC: functional class; 6MWD: 6-min walking distance; $V^{\prime} \mathrm{O}_{2}$ peak: peak oxygen uptake; BNP: brain natriuretic peptide; NT-proBNP: N-terminal pro-BNP: PE: pericardial effusion; TAPSE: tricuspid annular plane systolic excursion; RAP: right atrial pressure; Cl: cardiac index. ${ }^{\#}$ : depending on age, height, weight, aetiology of pulmonary arterial hypertension and presence of comorbidities. Adapted from [3] with permission from the publisher.

To summarise, this case described the disease course and management of an adult patient who presented with severe PAH (NYHA functional class IV) associated with mixed CTD. Pulmonary hypertension has been reported in 3-32\% of patients with mixed CTD [4-7], with PAH reported in only 1\% [4], and has been shown to persist despite treatment [7]. Inflammation is thought to play an important role in the development of PAH in CTD patients [8]. Autoantibodies have been implicated in the immunopathological processes involved [9]. It has been recognised that the immune and inflammatory mechanisms implicated in CTD-associated PAH support the use of immunosuppressants for its treatment, although the evidence to date is variable $[10,11]$. Patients with mixed CTD who are suspected to have cardiopulmonary involvement should be referred as early as possible to expert pulmonary hypertension centres for right heart catheterisation, as pre-capillary PAH should be confirmed prior to the initiation of PAH-specific therapies [10]. The patient presented here was treated by combining three PAH-specific therapies upfront, in addition to immunosuppressant therapy for the treatment of the underlying inflammatory processes.

In patients with severe $\mathrm{PAH}$, targeting more than one of the three known pathological pathways of PAH is common. In heart failure and malignant hypertension, or in diseases where mortality rates are high, an upfront pre-emptive approach is standard $[12,13]$. The evidence for combining treatments upfront is increasing in PAH, but is still very limited with regard to upfront triple-combination therapy [14]. The 5th World Symposium on Pulmonary Hypertension indicated that initial combination therapy may be considered (grade of evidence IIb-C) in patients in NYHA functional class III/IV [15]. More recently, a pilot study has investigated the benefit of upfront triple-combination therapy in 19 patients with $\mathrm{PAH}$ in NYHA functional class III/IV [2]. Patients with idiopathic and heritable PAH received upfront bosentan, sildenafil and i.v. epoprostenol. In 18 out of 19 patients, major improvements in NYHA functional class, 6MWD and haemodynamic parameters (including cardiac index, mPAP and PVR) were observed after 4 months and were sustained long-term. Moreover, all patients were still alive and in NYHA functional class I or II after a mean follow-up period of $41 \pm 13$ months.

Several case studies [16-20] and some larger retrospective studies [8, 21-23] have reported positive outcomes for patients with lupus- or mixed CTD-associated PAH treated with immunosuppressive therapy alone or in association with PAH-specific therapies. However, immunosuppressive therapy alone does not appear to be sufficient in patients with more severe haemodynamic impairment [8, 10, 22]. The case reported herein provides further weight for combining immunosuppressive therapy with triplecombination PAH therapy in treating a patient with severe mixed CTD-associated PAH.

Another important consideration that this case brings to light is how this patient, now in NYHA functional class I on immunosuppressive and triple-combination therapy, should be managed. In patients who respond favourably to treatment, an immunosuppressive maintenance regimen has been suggested [8]. 
There is also a need to determine if patients, such as the current case, should continue to receive i.v. epoprostenol or if, in specific patients, they can be weaned off this treatment. Varying outcomes following weaning of i.v. epoprostenol have been reported in adult patients with PAH. While some patients have been successfully weaned from epoprostenol to be maintained on oral or inhaled therapies, others have deteriorated, requiring re-initiation of i.v. epoprostenol [24-37]. Unfortunately, factors that may predict a patient's clinical response following epoprostenol weaning are difficult to define.

In conclusion, patients with complex pulmonary vascular diseases should be referred to expert centres as soon as possible in order to provide patients with the most appropriate treatment; close monitoring is essential. Upfront triple-combination therapy in conjunction with immunosuppressive therapy may provide benefit in patients with severe PAH associated with mixed CTD. Further evidence is needed to determine the optimal maintenance regimes for these patients.

\section{Acknowledgements}

Medical writing support was provided by Lynda McEvoy (apothecom scopemedical ltd, Sevenoaks, UK), which was funded by Actelion Pharmaceuticals Ltd (Allschwil, Switzerland).

\section{References}

1 Humbert M, Sitbon O, Chaouat A, et al. Survival in patients with idiopathic, familial, and anorexigen-associated pulmonary arterial hypertension in the modern management era. Circulation 2010; 122: 156-163.

2 Sitbon O, Jaïs X, Savale L, et al. Upfront triple combination therapy in pulmonary arterial hypertension: a pilot study. Eur Respir J 2014; 43: 1691-1697.

3 Galiè N, Hoeper MM, Humbert M, et al. Guidelines for the diagnosis and treatment of pulmonary hypertension. Eur Respir J 2009; 34: 1219-1263.

4 Gunnarsson R, Andreassen AK, Molberg Ø, et al. Prevalence of pulmonary hypertension in an unselected, mixed connective tissue disease cohort: results of a nationwide, Norwegian cross-sectional multicentre study and review of current literature. Rheumatology (Oxford) 2013; 52: 1208-1213.

5 Alpert MA, Goldberg SH, Singsen BH, et al. Cardiovascular manifestations of mixed connective tissue disease in adults. Circulation 1983; 68: 1182-1193.

6 Sullivan WD, Hurst DJ, Harmon CE, et al. A prospective evaluation emphasizing pulmonary involvement in patients with mixed connective tissue disease. Medicine (Baltimore) 1984; 63: 92-107.

7 Burdt MA, Hoffman RW, Deutscher SL, et al. Long-term outcome in mixed connective tissue disease: longitudinal clinical and serologic findings. Arthritis Rheum 1999; 42: 899-909.

8 Dorfmüller P, Perros F, Balabanian K, et al. Inflammation in pulmonary arterial hypertension. Eur Respir J 2003; 22: 358-363.

9 Okawa-Takatsuji M, Aotsuka S, Fujinami M, et al. Up-regulation of intercellular adhesion molecule-1 (ICAM-1), endothelial leucocyte adhesion molecule-1 (ELAM-1) and class II MHC molecules on pulmonary artery endothelial cells by antibodies against U1-ribonucleoprotein. Clin Exp Immunol 1999; 116: 174-180.

10 Jais X, Launay D, Yaici A, et al. Immunosuppressive therapy in lupus- and mixed connective tissue diseaseassociated pulmonary arterial hypertension: a retrospective analysis of twenty-three cases. Arthritis Rheum 2008; 58: 521-531.

11 Foïs E, Sitbon O. Systemic lupus erythmatosus-associated PAH: is targeting inflammation the key to success? Eur Respir Rev 2011; 20: 218-219.

12 Go AS, Mozaffarian D, Roger VL, et al. Heart disease and stroke statistics - 2014 update: a report from the American Heart Association. Circulation 2014; 129: e28-e292.

13 Amraoui F, Van Der Hoeven NV, Van Valkengoed IG, et al. Mortality and cardiovascular risk in patients with a history of malignant hypertension: a case-control study. J Clin Hypertens (Greenwich) 2014; 16: 122-126.

14 Ghofrani H-A, Humbert M. The role of combination therapy in managing pulmonary arterial hypertension. Eur Respir Rev 2014; 23: 469-475.

15 Galiè N, Corris PA, Frost A, et al. Updated treatment algorithm of pulmonary arterial hypertension. J Am Coll Cardiol 2013; 62: Suppl. 25, D60-D72

16 Watanabe R, Fujii H, Shirai T, et al. Successful use of intensive immunosuppressive therapy for treating simultaneously occurring cerebral lesions and pulmonary arterial hypertension in a patient with systemic lupus erythematosus. Intern Med 2014; 53: 627-631.

17 Prete M, Fatone MC, Vacca A, et al. Severe pulmonary hypertension as the initial manifestation of systemic lupus erythematosus: a case report and review of the literature. Clin Exp Rheumatol 2014; 32: 267-274.

18 Okura Y, Takezaki S, Yamazaki Y, et al. Rapid progression to pulmonary arterial hypertension crisis associated with mixed connective tissue disease in an 11-year-old girl. Eur J Pediatr 2013; 172: 1263-1265.

19 Kato M, Kataoka H, Odani T, et al. The short-term role of corticosteroid therapy for pulmonary arterial hypertension associated with connective tissue diseases: report of five cases and a literature review. Lupus 2011; 20: $1047-1056$.

20 Végh J, Soós G, Csipõ I, et al. Pulmonary arterial hypertension in mixed connective tissue disease: successful treatment with Iloprost. Rheumatol Int 2006; 26: 264-269.

21 Miyamichi-Yamamoto S, Fukumoto Y, Sugimura K, et al. Intensive immunosuppressive therapy improves pulmonary hemodynamics and long-term prognosis in patients with pulmonary arterial hypertension associated with connective tissue disease. Circ J 2011; 75: 2668-2674.

22 Sanchez O, Sitbon O, Jaïs X, et al. Immunosuppressive therapy in connective tissue diseases-associated pulmonary arterial hypertension. Chest 2006; 130: 182-189.

23 Tanaka E, Harigai M, Tanaka M, et al. Pulmonary hypertension in systemic lupus erythematosus: evaluation of clinical characteristics and response to immunosuppressive treatment. J Rheumatol 2002; 29: 282-287. 

(prostacyclin) administration in severe pulmonary hypertension. Chest 2001; 119: 296-300.

25 Vachiéry JL, Hill N, Zwicke D, et al. Transitioning from i.v. epoprostenol to subcutaneous treprostinil in pulmonary arterial hypertension. Chest 2002; 121: 1561-1565.

26 Kim NH, Channick RN, Rubin LJ. Successful withdrawal of long-term epoprostenol therapy for pulmonary arterial hypertension. Chest 2003; 124: 1612-1615.

27 Suleman N, Frost AE. Transition from epoprostenol and treprostinil to the oral endothelin receptor antagonist bosentan in patients with pulmonary hypertension. Chest 2004; 126: 808-815.

28 Gomberg-Maitland M, Tapson VF, Benza RL, et al. Transition from intravenous epoprostenol to intravenous treprostinil in pulmonary hypertension. Am J Respir Crit Care Med 2005; 172: 1586-1589.

29 Steiner MK, Preston IR, Klinger JR, et al. Conversion to bosentan from prostacyclin infusion therapy in pulmonary arterial hypertension: a pilot study. Chest 2006; 130: 1471-1480.

30 Johnson RF, Loyd JE, Mullican AL, et al. Long-term follow-up after conversion from intravenous epoprostenol to oral therapy with bosentan or sildenafil in 13 patients with pulmonary arterial hypertension. J Heart Lung Transplant 2007; 26: 363-369.

31 Rubenfire M, McLaughlin VV, Allen RP, et al. Transition from IV epoprostenol to subcutaneous treprostinil in pulmonary arterial hypertension: a controlled trial. Chest 2007; 132: 757-763.

32 Safdar Z. Outcome of pulmonary hypertension subjects transitioned from intravenous prostacyclin to oral bosentan. Respir Med 2009; 103: 1688-1692.

33 Park K, Ostrow D, Levy RD, et al. Transition from intravenous epoprostenol to oral or subcutaneous therapy in pulmonary arterial hypertension: a retrospective case series and systematic review. Can Respir J 2011; 18 : $157-162$.

34 de Jesus Perez VA, Rosenzweig E, Rubin LJ, et al. Safety and efficacy of transition from systemic prostanoids to inhaled treprostinil in pulmonary arterial hypertension. Am J Cardiol 2012; 110: 1546-1550.

35 Enderby CY, Soukup M, Al Omari M, et al. Transition from intravenous or subcutaneous prostacyclin therapy to inhaled treprostinil in patients with pulmonary arterial hypertension: a retrospective case series. J Clin Pharm Ther 2014; 39: 496-500.

36 Diaz-Guzman E, Heresi GA, Dweik RA, et al. Long-term experience after transition from parenteral prostanoids to oral agents in patients with pulmonary hypertension. Respir Med 2008; 102: 681-689.

37 Minai OA, Parambil J, Dweik RA, et al. Impact of switching from epoprostenol to IV treprostinil on treatment satisfaction and quality of life in patients with pulmonary hypertension. Respir Med 2013; 107: 458-465. 